\title{
Techniques for Writing Chapter I of Research and Development in Public Health
}

\section{Phongpisanu B*}

Sirindhorn College of Public Health Phitsanulok, Praboromarajchanok Institute of Health Workforce Development, Ministry of Public Health, Thailand

*Corresponding author: Dr. Phongpisanu Boonda, Sirindhorn College of Public Health Phitsanulok, Praboromarajchanok Institute of Health Workforce Development, Ministry

Conceptual Paper

Volume 3 Issue 3

Received Date: May 08, 2019

Published Date: May 31, 2019

DOI: $10.23880 / \mathrm{mjccs}-16000222$ of Public Health, Thailand, Tel: +66 (0) 81 7859503, +66 (0) 55 313114; Fax: +66 (0) 55 313116; Email: phong2470@hotmail.com

\section{Abstract}

Outline of Chapter I in general research consists of title, introduction, research questions, purpose statements, hypothesis, scopes of research, definitions, and benefits which research and development in public health has the same approach that must point out the condition of the research problem by showing information confirming the problem then identify ideas for solving problems determine the purposes of research, scopes of research and the benefits expected to be received clearly.

Techniques for writing Chapter I of research and development in public health of this article there is a distinctive feature that divides the scope of research into 4 areas that consist of content scope, data resource scope, variable scope, and instrument scope to be a guideline for researchers create clarity in the preparation of the research proposal.

Keywords: Chapter I; Research and development; Public health

\section{Introduction}

Research and Development is one of the research characteristics that great benefit to the task development, professional development or development of human lifestyle. Currently, many organizations have tried to encourage personnel affiliated with the knowledge and ability in research and development. It is believed that research and development will provide new alternatives or methods. This will help to increase the efficiency of the operation which has the history and the long evolution to create innovation both science invention, world industry, and the business of the western world. Causing many important products of the world which has roles the thoughts and changes of human life as well as impacting changes continuously from past to present such as the discovery of vaccines, the invention of light bulb, development of machinery for production in industrial production, telephone, refrigerator, invented the method of contraception, the development of computer, and the birth of the Internet which have the greatest impact on communication of mankind, etc. The concept of research and development (R\&D) can create breakthrough ideas and invent new invention of all disciplines such as scientific, industrial medicine, social sciences, humanities, arts, etc [1]. 


\section{Medical Journal of Clinical Trials \& Case Studies}

Before beginning the paper, researchers need to decide how researchers plan to design the study. The research design refers to the overall strategy that researchers choose to integrate the different components of the study in a coherent and logical way, thereby, ensuring researchers will effectively address the research problem; it constitutes the blueprint for the collection, measurement, and analysis of data.

Chapter outline as a general guideline includes Chapter 1: Introduction, Chapter 2: Literature Review, Chapter 3: Research Methodology, Chapter 4: Results, and Chapter 5: Discussion and Recommendations for Future Research. In the part of Chapter I, the outline of in general research consists of the title, introduction, research questions, purpose statements, hypothesis, scopes of research, definitions, and benefits which research and development have the same approach.

From the above information in conducting public health research and development, there is a no different approach. Just how to make researchers can do research quickly especially in Chapter 1 which must point out the condition of the research problem by showing information confirming the problem then identify ideas for solving problems determine the purposes of research, scopes of research and the benefits expected to be received clearly. Having techniques for writing Chapter I of research and development in public health of this article will be a technique to help researchers create clarity in the preparation of the research proposal.

\section{Writing Chapter I for Research and Development in Public Health}

How to write Chapter I for a proposal of doing research and development in public health? The focus of this chapter must point out the condition of the research problem, problems will take place in 3 parts of the SIPOC Model are SIP in part of OC are just monitor. When the problems have been analyzed then set priority the most important issues to determine the root causes with the fishbone diagram to solve the root causes. Phongpisanu B [2] by showing information confirming the problem then identify ideas for solving problems determine the purposes of research, scopes of research and the benefits expected to be received clearly which in this article will use the conceptual framework of Phongpisanu Boonda for writing. Let's take a look at how to write Chapter I [2].

\section{Writing Title}

After that use SIPOC Model for analyzing own works details and already found the cause of the problem use words "model and/or as three types (machine/material, curriculum/program/activity, and process) of innovation or etc." to demonstrate the goals of development next to the word "Development of.....to....." and followed with phrases that expand the pattern as the structures of the topic as follows:

Development of +.....Model.....to + phrases

Development of +.....Machine/material.....to + phrases

Development of + .....Curriculum/program/activity.....to + phrases

Development of $+\ldots . .$. Process .....to + phrases

Development of + .....etc......to + phrases

In all 5 structures, researchers can sort new words according to grammar principles in sentences to reduce preposition and concise title structures.

Example: "Effect of an Operational Competency Development Model of Public Health Personnel in the Virtual Service Provider Office (VSPO) in Thailand"

\section{Writing Introduction}

By using components of writing a good introduction of Creswell [3] as a guide to explain

Please use the keyword's title to start and classify the elements of the keyword in order to select the subkeyword from the first layer which is [3] establishing the problem leading to the study.

\section{Example:}

Title: "Effect of an Operational Competency Development Model of Public Health Personnel in the Virtual Service Provider Office (VSPO) in Thailand"

Introduction: The VSPO Management Model (VSPOMM) for service plan (SP) in the Second Regional Health Service in Thailand was composed of 7 factors from 74 selected variables, as follows: (1) providing administration and management for everyone, regardless of time and place, as of media and technologies fit in any way; (2) establishing administration by collaboration and clearinghouse; (3) supporting technical services both in the system and outside the system in academic administration; (4) instituting stakeholder support system in the network of general administration; (5) freedom in budget administration, especially in the information technology development; (6) personnel administration with new management and information technology skills; (7) operating support resources 


\section{Medical Journal of Clinical Trials \& Case Studies}

management, including management cockpit, document and URL web link, and using web technology applications [4].

Then classify the elements of the sub keyword again. Do this continuously until you reach the point of the word that is the issue to be used to find the cause and solve the problem by research which is [3] reviewing the literature about the problem, identifying deficiencies in the literature about the problem, targeting an audience and noting the significance of the problem for this audience, and identifying the purpose of the proposed study.

\section{Example:}

They put into consideration the concept of virtual reality created by a computer to establish an organization, so it may be of no physical shape, which is a characteristic that is different from traditional organizations in general. However, the definition of virtual organizations refers to the network of organizations linked by information technology in order to share operational skills and resources [5] through the use of telecommunications, technology, social, and community networks, which are interdependent in terms of cooperation, flexibility, trust, and self-organization [6]. The scope of the organization has an unclear boundary and location, which is expected to be useful in the adoption of VSPOMM for SP and in performing effectively.

"VSPO" is a new key management mechanism created to realize the health service system development plans and also a mechanism established to bring about the integration of all elements of the health system. However, this VSPO to support the work of the executive has not yet been formally deployed (in terms of operations and practitioners), and there are no training programs instituted yet, which are based on necessary factors to develop the competency of public health personnel in each province. Researchers are interested in the education aspect of the operational competency development model of public health personnel in the VSPO in Thailand, which is a new model intended to solve the problems mentioned above.

\section{Writing Research Questions}

Research and development is a strong mixed methods study that should contain the qualitative question, the quantitative question or hypothesis, and a mixed methods question. This configuration is necessary because mixed methods do not rely exclusively on either qualitative or quantitative research but on both forms of inquiry.
Researchers should consider what types of questions should be presented and when and what information is most needed to convey the nature of the study:

- Both qualitative and quantitative research questions (or hypotheses) need to be advanced in a mixed methods study in order to narrow and focus the purpose statement. These questions or hypotheses can be advanced at the beginning or when they emerge during a later phase of the research. For example, if the study begins with a quantitative phase, the investigator might introduce hypotheses. Later in the study, when the qualitative phase is addressed, the qualitative research questions appear.

- When writing these questions or hypotheses, follow the guidelines in this chapter for scripting good questions or hypotheses.

- Some attention should be given to the order of the research questions and hypotheses. In a two-phase project, the first-phase questions would come first, followed by the second-phase questions so that readers see them in the order in which they will be addressed in the proposed study. In a single phase strategy of inquiry, the questions might be ordered according to the method that is given the most weight or priority in the design.

- In addition to quantitative questions/hypotheses and qualitative questions, include a mixed methods research question that directly addresses the mixing of the quantitative and qualitative strands of the research. This is the question that will be answered in the study based on the mixing [7]. This is an innovative form of a question in research methods, and Tashakkori and Creswell [8] call it a "hybrid" or "integrated" question. This mixed methods question could either be written at the beginning of a study or when it emerges during a study.

For instance, in a single-phase study in which quantitative and qualitative data are collected simultaneously and merged, the question of the mixed methods could be advanced at the outset in the study. However, in a two-phase study in which one phase builds on the other, the mixed methods questions might be placed in a discussion between the two phases.

- The mixed methods question can be written in different ways. This can assume one of three forms.

- The first is to write it in a way that conveys the methods or procedures in a study

(e.g., Does the qualitative data help explain the results from the initial quantitative phase of the study?). 


\section{Medical Journal of Clinical Trials \& Case Studies}

- The second form is to write it in a way that conveys the content of the study

(e.g., Does the theme of social support help to explain why some students become bullies in schools?) [8].

- The third approach is to combine the methods and content

(e.g., How does the qualitative interview data on student bullying further explain why social support, as measured quantitatively, tends to discourage bullying as measured on a bullying scale?).

- Consider how to present the quantitative, qualitative, and mixed methods questions in a mixed method. An ideal format would be to write the questions into separate sections, such as the quantitative questions or hypotheses, the qualitative questions, and the question of the mixed methods. This format highlights the importance of all three sets of questions and draws the readers' attention to the separate quantitative and qualitative strands coming together (or being integrated) in a mixed methods study. Place the question of the mixed methods (written in methods or content or some combination form) last because the study will build to this element of the design.

Example 1: Hypothesis and Research Questions in a Mixed Methods Study Houtz [9] provided an example of a two-phase study with the separate quantitative and qualitative research hypotheses and questions stated in sections introducing each phase. She did not use a separate, distinct mixed methods research question because such a question had not been developed at the time of her project. Nevertheless, her study was a rigorous mixed methods investigation. She studied the differences between middle school (nontraditional) and junior high (traditional) instructional strategies for seventh-grade and eighth-grade students and their attitudes toward science and science achievement. Her study was conducted at a point when many schools were moving away from the 2-year junior high concept to the 3 -year middle school (including sixth grade) approach to education.

In this two-phase study, the first phase involved assessing pretest and posttest attitudes and achievement using scales and examination scores. Houtz then followed the quantitative results with qualitative interviews with science teachers, the school principal, and consultants. This second phase helped to explain the differences and similarities in the two instructional approaches obtained in the first phase. With a first-phase quantitative study,
Houtz [9] mentioned the hypotheses guiding her research: It was hypothesized that there would be no significant difference between students in the middle school and those in the junior high in attitude toward science as a school subject. It was also hypothesized that there would be no significant difference between students in middle school and those in the junior high in achievement in science (p. 630). These hypotheses appeared at the beginning of the study as an introduction to the quantitative phase. Prior to the qualitative phase, Houtz [9] raised questions to explore the quantitative results in more depth. Focusing in on the achievement test results, she interviewed science teachers, the principal, and the university consultants and asked three questions:

- What differences currently exist between the middle school instructional strategy and the junior high instructional strategy at this school in transition?

- How has this transition period impacted the science attitude and achievement of your students?

- How do teachers feel about this change process? (p. 649)

Examining this mixed methods study closely shows that the author included both quantitative and qualitative questions, specified them at the beginning of each phase of her study, and used good elements for writing both quantitative hypotheses and qualitative research questions. Had Houtz [9] developed a mixed methods question, it might have been stated from a procedural perspective:

- How do the interviews with teachers, the principal, and university consultants help to explain any quantitative differences in achievement for middle school and junior high students? (Methods orientation).

Alternatively, the question of the mixed methods might have been written from a content orientation, such as the following:

- How do the themes mentioned by the teachers help to explain why middle-school children score lower than the junior high students? (Content orientation).

\section{Example 2: A Mixed Methods Question Written Using Methods and Content-Language}

- To what extent and in what ways do qualitative interviews with students and faculty members serve to contribute to a more comprehensive and nuanced understanding of this predicting relationship between CEEPT scores and student academic performance, via integrative mixed methods analysis? [10]

This is a good example of a mixed methods question focused on the intent of mixing, to integrate the qualitative interviews and the quantitative data, the relationship of scores and student performance. This 


\section{Medical Journal of Clinical Trials \& Case Studies}

question emphasized what the integration was attempting to accomplish - a comprehensive and nuanced understanding - and at the end of the article, the authors presented evidence answering this question.

Example 3: A Mixed Methods Question Written Using Steps of Research and development (Phongpisanu B.,2018)

Research Question 1: $\quad$ Situation, problem, and need of..... (Title) .........How it is?

Guidelines of (Model) How it is?

Example: The need and guidelines for improving competency among

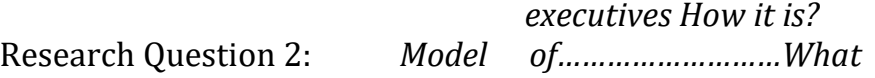
are the components?

Example:

The training program in order to develop the competency of regional operating officers (ROOs) in the VSPO in Thailand using the EFA and 2nd Order CFA What are the components?

Example: The training program to develop the competency of ROOs in the VSPO in Thailand Is it appropriate/Quality?

Research Question 3: $\quad$ Model of........................ Is it efficiency/ effectiveness?

Example: The training program to develop the competency of ROOs in the VSPO in Thailand Is it efficiency/ effectiveness?

Research Question 4: Evaluation results of............... (Model) ............How is it?

Example: Evaluation of a training program to develop the competency of ROOs in the VSPO in Thailand How is it?

\section{Writing Purpose Statements}

Research questions item 3.1-3.4 related with purpose statements item 4.1-4.4, respectively and use four research questions (item 3.1-3.4) to change sentence by changing "questions sentence" to be "To+V.1+Obj." as details of item 4.1-4.4

Research Objective 1: To study situation, problem, and need of...... (Title) ............

And to study guidelines of. (Model)

Example: To analyze the need and guidelines for improving competency among executives

Example: To analyze the factors of the training program in order to develop the competency of regional operating officers (ROOs) in the VSPO in Thailand using the EFA and $2^{\text {nd }}$ Order CFA.
Research Objective 2: To create and to audit. .. (Model)

Example: To design (create and audit) an appropriate training program to develop the competency of ROOs in the VSPO in Thailand

Research Objective 3: $\quad$ To experiment and study results of using.... (Model) ............

Example: To experiment and study results (Formative Evaluation) of using the training program to develop the competency of ROOs in the VSPO in Thailand Research Objective 4: To evaluate of. (Model)

Example: To evaluate (Summary Evaluation) the satisfaction of using the training program to develop the competency of ROOs in the VSPO in Thailand

\section{Writing Hypothesis}

Researchers may be defined hypotheses related with purpose statement item 4.1-4.4. However, hypothesis testing every item is required. Or hypothesis determined by the results of the experiment in step 3 of the research as follows "scores will be higher for Group A than for Group B" on the dependent variable or that "Group A will change more than Group B" because the main goal of the research and development is at the trial results.

Research hypothesis 1: Analysis results ...... (Situations, problems, needs and guidelines)...... can be used as information for modeling

Example: Analysis results the need and guidelines for improving competency among executives can be used as information for creating elements of the training program in order to develop the competency of regional operating officers (ROOs) in the VSPO in Thailand

Example: Analysis results the factors of the training program in order to develop the competency of regional operating officers (ROOS) in the VSPO in Thailand using the EFA and $2^{\text {nd }}$ Order CFA can be used as information for the training program in order to develop the competency of regional operating officers (ROOS) in the VSPO in Thailand

Research hypothesis 2: .........(Model) ........ was quality at a high level

Example: - a Training program to develop the competency of ROOs in the VSPO in Thailand was quality at a high level Research hypothesis 3: .........(Model) ......... was effective at a high level

Example: - a Training program to develop the competency of ROOs in the VSPO in Thailand was effective at a high level 


\section{Medical Journal of Clinical Trials \& Case Studies}

- Post-test knowledge scores of ROOs will be higher Pretest after using the training program to develop the competency of ROOs in the VSPO in Thailand

- Post-test skills scores of ROOs will be higher criteria after using the training program to develop the competency of ROOs in the VSPO in Thailand

- Post-test competency scores of ROOs will be higher criteria after using the training program to develop the competency of ROOs in the VSPO in Thailand

Research hypothesis 4: $\quad$ The samples were satisfied with ...... (Model) ...... at a high level

Example: ROOs in the VSPO in Thailand were satisfied with using the training program to develop the competency

\section{Writing scopes of research (Based on purpose statements)}

Step 1: Expanding research objective of item 4.1 by changing word "To study (To+V.1)" to be "Studying (V.1+ing)"

i. Content scope: Studying situation, problem, and need of...(Title).......which includes.

Example: Study and review of situations, problems, and guidelines for operational competency development

- Analyzing the VSPOMM factors for SP in the regional health service in Thailand

ii. Data resource scope: Indicates the population used in the study, which may behave both primary data and/or secondary data.

Example: 1) The population used in the development of the components consisted of qualified members of the health services system in the VSPO of the regional health service, and the executives and practitioners in the vice chief of the provincial health office in the 12 health service virtualization regions of Thailand.

2) Sampling size used in the study consisted of two groups: (1) group of highly qualified experts of nearby health services system in the VSPO of the regional health service in Thailand, of which 274 were selected by network sampling; (2) to develop the confirmatory factor, 664 administrators and practitioners in the field of health services and VOs were selected by multistage random sampling covering all geographical regions and including executives and workers from other parts of Thailand.

iii. Variable scope: Indicates the variables studied were...(details of the situation, problem, and need)

Example: Indicates the variables studied were VSPOMM factors for SP in the regional health service in Thailand
iv.Instrument scope: Indicates instrument for primary data and/or secondary data...... (Such as form for interviewing, recording, surveying)...............

Example: 1) Tools used in research: The instrument used for data collection consisted of the questionnaire that the researchers created. Two versions of the questionnaire were distributed among qualified administrators and practitioners in the field offices of the Virtual Health Services. (1) The questionnaire for luminaries was used to collect information for the development of components. It is a survey of the experts' opinions on a list of variables (90) on the form of the VSPOMM for service plans in regional health service in Thailand. (2) The questionnaire for the management and practitioners in the Virtual Service Provider Office of Thailand was the tool used to collect information for the development of component-oriented confirmation.

2) Data analysis: Developed by two elements: (1) Experts, who created the master of studies and research-related documents, and then used it as a framework to create a query. The survey collected the data from a sample of experts and analyzed it with EFA. (2) CFA, which introduces elements that are developed by experts in the framework of item (1) (above) to create a query, and a questionnaire to collect data from managers and practitioners in the 12 of VSPO of the regional health service in Thailand, and then analyzed with the $2^{\text {nd }}$ Order CFA.

Step 2: Expanding the research objective of item 4.2 by changing the word "To create and to audit (To+V.1)" to be "Creating and Auditing (V.1+ing)" and classified into 2 sections for clarity.

\section{Creating Model}

i. Content scope: Indicates knowledge to use for creating model.........

Example: Indicates knowledge to use for the creation of the operational competency development model components by analysis and synthesis of data gathered from the first stage

- Analyzing the factors of the training program to develop the competency of ROOs in the VSPO in Thailand.

ii. Data resource scope: Indicate documents, books, and related researches...

Example: 1) The population: Indicate documents, books, and related researches about factors of the training program to develop the competency of ROOs in the VSPO

2) Sampling size: Matrix of factors of the training program to develop the competency of ROOs in the VSPO from Indicate documents, books, and related researches 


\section{Medical Journal of Clinical Trials \& Case Studies}

iii. Variable scope: Indicates the independent variables and dependent variables

Independent variables: Information from analyzing and synthesizing data in step 1-2

Dependent variables: Draft of components of the model

Example: Independent variables: Information from analyzing and synthesizing data from indicating documents, books, and related researches about factors of the training program to develop the competency of ROOs in the VSPO

- Dependent variables: Draft of components of the training program to develop the competency of ROOs in the VSPO in Thailand

iv.Instrument scope: Instrument for documents, books, and related researches is formed recording information

Example: 1) Tools used in research: Form for documents, books, and related researches is form recording information

2) Data analysis: document analysis was used

\subsubsection{Auditing Model}

i. Content scope: Considering components of model................

Example: Justification of the operational competency development model components

- Analyzing the factors of the training program to develop the competency of ROOs in the VSPO in Thailand.

- Designing the training program to develop the competency of ROOs in the VSPO in Thailand.

ii. Data resource scope: Experts, Strake holders..

Example: 1) The population used in the development of the components referred to qualified members of the health services system in the VSPO of the regional health service and the executives and practitioners in the vice chief of the provincial health office in the 12 health service virtualization regions of Thailand. And experts in terms of designing the training program to develop competency

2) Sampling size used in the study consisted of two groups: (1) 274 highly qualified experts of nearby health services system in the VSPO of the regional health service in Thailand, who were selected by network sampling; (2) to develop the confirmatory factor, 664 administrators and practitioners in the field of health services and VOs who were selected by multistage random sampling covering all geographical regions and including executives and workers from other parts of Thailand and 15 experts who were selected by purposive sampling. iii. Variable scope: Indicates the independent variables and dependent variables

Independent variables: Draft of components of the model Dependent variables: Quality of components of the model

Example: Independent variables: Components of the training program to develop the competency of ROOs in the VSPO in Thailand

Dependent variables: Quality of the training program to develop the competency of ROOs in the VSPO in Thailand

iv.Instrument scope: Instrument for auditing model of experts and stakeholders are evaluation form and questionnaires, respectively

Example: 1) Tools used in research: The instrument used for data collection consisted of a questionnaire that the researchers created. Two versions of the questionnaire were distributed among qualified administrators and practitioners in the field offices of the Virtual Health Services.

1. The questionnaire for luminaries was used to collect information for the development of components. It is a survey of the experts' opinions on a list of variables (40) on the form of the training program factors to develop the competency of ROOs in the VSPO in Thailand.

2. The questionnaire for administrators and practitioners in the VSPO of Thailand was the tool used to collect information for the development of component-oriented confirmation.

3. Form for focus group discussion

2) Data analysis: Developed by two elements:

1. Experts who created the master of studies and research related documents, and then used it as a framework to create a query. The survey collected the data from a sample of experts and analyzed it with EFA.

2. CFA, which introduces elements that are developed by experts in the framework of item (1) (above) to create a query, and a questionnaire to collect data from managers and practitioners in the 12 of VSPO of the regional health service in Thailand, and then analyzed with the $2^{\text {nd }}$ Order CFA.

3. Content analysis was used

4.6.3. Step 3: Expanding research objective of item 4.3 by changing the word "To experiment and study (To+V.1)" to be "Experimenting and Studying (V.1+ing)"

i. Content scope: Components model.................................

Example: Developing the operational competency of public health personnel 


\section{Medical Journal of Clinical Trials \& Case Studies}

- Using the training program to develop the competency of ROOs in the VSPO in Thailand

ii. Data resource scope: Indicates study group/ experiment group

Example: 1) Population: This consisted of executives on various aspects, and practitioners in the Vice Chief of the Provincial Health Office in the Second Regional Health Service (Phitsanulok, Tak, Uttaradit, Sukhothai, and Phetchabun).

2) Sampling size: This consisted of 15 executives, as well as practitioners in the Vice Chief of the Provincial Health office (regional operating officer) in the five provinces (five for each province, for a total of 25). Groups studied in this research were selected by purposive sampling. These individuals are those who have a deep understanding of the executive office of health services or those who are used to performing tasks related to health services, including in field offices.

iii. Variable scope: Indicates the independent variables and dependent variables

Independent variables: Using model.

Dependent variables: Effectiveness/ Efficiency of model..

Example: Independent variables: Using the training program of four modules

Dependent variables: Efficiency of the training program of four modules

iv.Instrument scope: Instrument for formative evaluation model of study group/ experiment group are experiment form

Example: 1) Tools used in research: Form for formative evaluation of using the training program to develop the competency of ROOs in the VSPO in Thailand of four modules and focus group discussion.

2) Data analysis: Data were analyzed using percentage, mean, and content analysis.

Step 4: Expanding research objective of item 4.4 by changing the word "To evaluate (To+V.1)" to be "Evaluating (V.1+ing)"

i. Content scope: the satisfaction of using the model

Example: Evaluating (Summary Evaluation) the satisfaction of using the training program to develop the competency of ROOs in the VSPO in Thailand

- the satisfaction of using the training program to develop the competency of ROOs in the VSPO in Thailand ii. Data resource scope: Indicates study group/ experiment group...

Example: 1) Population: This consisted of executives on various aspects, and practitioners in the Vice Chief of the Provincial Health Office in the Second Regional Health Service (Phitsanulok, Tak, Uttaradit, Sukhothai, and Phetchabun).

2) Sampling size: This consisted of 15 executives, as well as practitioners in the Vice Chief of the Provincial Health Office (regional operating officer) in the five provinces (five for each province, for a total of 25). Groups studied in this research were selected by purposive sampling. These individuals are those who have a deep understanding of the executive office of health services or those who are used to performing tasks related to health services, including in field offices.

iii. Variable scope: Indicates the variables studied were...(the satisfaction, context, input, process, productivity, etc.).

Example: Indicates the variables studied were the satisfaction of using the training program to develop the competency of ROOs in the VSPO in Thailand

iv.Instrument scope: Instrument for summative evaluation model of study group/ experiment group are experiment form

Example: 1) Tools used in research: Form for summative evaluation of using the training program to develop the competency of ROOs in the VSPO in Thailand of four modules and focus group discussion.

2) Data analysis: Data were analyzed mean and standard deviation

\section{Writing definitions}

To bring the title to the beginning

Define meaningful words from research titles by starting from the end of the research title then consider the words or phrases and their meanings until the last word or phrase of the research title

Create the meaning of each word which must be operationally used for research on the subject to be done Example:

\begin{tabular}{|c|c|}
\hline $\begin{array}{l}\text { To bring the } \\
\text { title to the } \\
\text { beginning }\end{array}$ & $\begin{array}{c}\text { Effect of an Operational Competency } \\
\text { Development Model of Public Health } \\
\text { Personnel in the Virtual Service } \\
\text { Provider Office (VSPO) in Thailand }\end{array}$ \\
\hline $\begin{array}{c}\text { Define } \\
\text { meaningful }\end{array}$ & $\begin{array}{l}\text { 1. Virtual Service Provider Office } \\
\text { (VSPO) }\end{array}$ \\
\hline $\begin{array}{l}\text { words from } \\
\text { research titles }\end{array}$ & $\begin{array}{l}\text { 2. Public Health Personnel in the } \\
\text { Virtual Service Provider Office }\end{array}$ \\
\hline
\end{tabular}




\section{Medical Journal of Clinical Trials \& Case Studies}

\begin{tabular}{|c|c|}
\hline $\begin{array}{l}\text { by starting } \\
\text { from the end of } \\
\text { the research } \\
\text { title then } \\
\text { consider the } \\
\text { words or } \\
\text { phrases and } \\
\text { their meanings } \\
\text { until the last } \\
\text { word or phrase } \\
\text { of the research } \\
\text { title }\end{array}$ & $\begin{array}{l}\text { (VSPO) } \\
\text { 3. Operational Competency of Public } \\
\text { Health Personnel in the Virtual } \\
\text { Service Provider Office (VSPO) } \\
\text { 4. An Operational Competency } \\
\text { Development Model of Public } \\
\text { Health Personnel in the Virtual } \\
\text { Service Provider Office (VSPO) }\end{array}$ \\
\hline $\begin{array}{l}\text { Create the } \\
\text { meaning of } \\
\text { each word } \\
\text { which must be } \\
\text { operationally } \\
\text { used for } \\
\text { research on the } \\
\text { subject to be } \\
\text { done }\end{array}$ & $\begin{array}{l}\text { Ex. Operational Competency of } \\
\text { Public Health Personnel in the } \\
\text { Virtual Service Provider Office } \\
\text { (VSPO) means: Knowledge, skills and } \\
\text { produce the necessary images to } \\
\text { perform work efficiently and } \\
\text { effectively Which is a characteristic } \\
\text { of public health personnel that } \\
\text { affects Operational of Public Health } \\
\text { Personnel in the Virtual Service } \\
\text { Provider Office }\end{array}$ \\
\hline
\end{tabular}

\section{Writing benefits}

To write in the manner that results after the research is completed such as: for planning in the organization, for further research, to be used as a corporate policy.

Example: - Use for planning to develop the competency of ROOs in the VSPO in Thailand

\section{Conclusion}

This article identified essential components in writing a method section in a proposal for a Chapter I. The outline of Chapter I began with defining a title by using words "model and/or as three types (machine/material, curriculum/program/activity, and process) of innovation or etc." to demonstrate the goals of development next to the word "Development of.....to....." and followed with phrases that expand the pattern

In the introduction use five components of writing a good introduction of Creswell [3] as a guide to explain include:

1) Establishing the problem leading to the study

2) Reviewing the literature about the problem

3) Identifying deficiencies in the literature about the problem
4) Targeting an audience and noting the significance of the problem for this audience

5) Identifying the purpose of the proposed study

The identification of research questions use hypotheses and research questions in a mixed methods study of Houtz [9], a mixed methods question written using methods and content language of Lee \& Greene [10], and a mixed methods question written using steps of research and development of Phongpisanu Boonda [2].

The identification of purpose statements by bringing research questions item 3.1-3.4 that related with purpose statements item 4.1-4.4, respectively and use four research questions (item 3.1-3.4) to change sentence by changing "questions sentence" to be "To+V.1+Obj." as details of item 4.1-4.4.

The identification of hypothesis researchers may be defined as a hypothesis related to purpose statement item 4.1-4.4. However, hypothesis testing every item is required. Or hypothesis determined by the results of the experiment in step 3 of the research as follows "scores will be higher for Group A than for Group B" on the dependent variable or that "Group A will change more than Group B" because the main goal of the research and development is at the trial results.

The identification of scopes of research

1) Step 1: Expanding research objective of item 4.1 by changing the word "To study (To+V.1)" to be "Studying (V.1+ing)"

2) Step 2: Expanding the research objective of item 4.2 by changing the word "To create and audit (To+V.1)" to be "Creating and Auditing (V.1+ing)" and classified into 2 sections for clarity.

3) Step 3: Expanding the research objective of item 4.3 by changing the word "To experiment and study (To+V.1)" to be "Experimenting and Studying (V.1+ing)"

4) Step 4: Expanding research objective of item 4.4 by changing word "To evaluate (To+V.1)" to be "Evaluating (V.1+ing)"

Writing definitions,

1) To bring the title to the beginning

2) Define meaningful words from research titles by starting from the end of the research title then consider the words or phrases and their meanings until the last word or phrase of the research title

3) Create the meaning of each word which must be operationally used for research on the subject to be done 


\section{Medical Journal of Clinical Trials \& Case Studies}

Writing benefits to write in the manner that results after the research is completed such as: for planning in the organization, for further research, to be used as a corporate policy.

which research and development in public health must point out the condition of the research problem by showing information confirming the problem then identify ideas for solving problems determine the purposes of research, scopes of research and the benefits expected to be received clearly.

\section{References}

1. Sirichai Kanjanawasee (2016) Research and Development for Thai Education. Silpakorn Educational Research Journal 8(2).

2. Phongpisanu B (2018) Main Steps of Doing Research and Development in Public Health. Med J Clin Trials Case Stud 2(10): 000183.

3. Creswell John W (2014) Research design: qualitative, quantitative, and mixed methods approach $4^{\text {th }}(E d n$.$) ,$ Thousand Oaks, CA: Sage.

4. Phongpisanu B (2014) Developing an appropriate Virtual Service Provider Office Management Model for Service Plan in the Second Regional Health Service of Ministry of Public Health in Thailand', in Proceedings of
Second International Conference on Global Public Health, pp: 54-59.

5. Travica B (1997) The design of the virtual organization: A research model. In: Proceedings of the American Conference on Information Systems, pp: 417-419.

6. Faucheux C (1997) How virtual organizing is transforming management science. Communication of the ACM 40(9): 50-55.

7. Creswell JW, Plano Clark VL (2011) Designing and conducting mixed methods research $2^{\text {nd }}$ (Edn.), Thousand Oaks, CA: Sage.

8. Tashakkori A, Creswell JW (2007) Exploring the nature of research questions in mixed methods research. Journal of Mixed Methods Research 1(3): 207-211.

9. Houtz LE (1995) Instructional strategy change and the attitude and achievement of seventh-and eighthgrade science students. JRST 32(6): 629-648.

10. Lee YJ, Greene J (2007) The Predictive Validity of an ESL Placement Test: A Mixed Methods Approach. Journal of Mixed Methods Research 1(4): 366-389. 